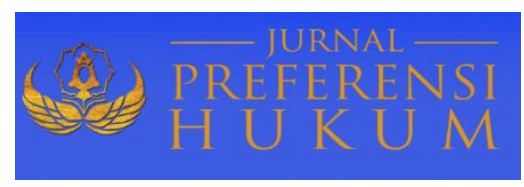

Jurnal Preferensi Hukum | ISSN: XXXX | E-ISSN: XXXX

Vol. 1 No. 1 - Juli 2020 hal. 68-73| Available online at https://www.ejournal.warmadewa.ac.id/index.php/juprehum

\title{
EKSISTENSI HAK GADAI TANAH SAWAH DI DESA UBUNG KECAMATAN JONGGAT KABUPATEN LOMBOK TENGAH NUSA TENGGARA BARAT
}

\author{
I Made Adi Karsa, Ida Ayu Putu Widiati, I Wayan Arthanaya \\ Fakultas Hukum Universitas Warmadewa, Denpasar-Bali, Indonesia
}

\begin{abstract}
Abstrak
Dengan berlakunya Undang-Undang Nomor 5 Tahun 1960 tentang Peraturan Dasar Pokok-pokok Agraria pada tanggal 24 September 1960 (UUPA), maka menghapus hukum agrarian lama. Tujuan penelitian ini yaitu menganalisis pelaksanaan gadai tanah di desa ubung kecamatan jonggat dan mengetahui faktor-faktor penghambat pelaksanaan gadai tanah pertanian di Desa Ubung Kecamatan Jonggat Kabupaten Lombok Tengah Nusa Tenggara Barat berdasarkan Undang-Undang Nomor 56 Prp Tahun 1960. Metode penelitian ini adalah metode penelitian empiris dengan menggunakan pendekatan sosiologi hukum. Hasil penelitian menunjukan bahwa gadai tanah pertanian dilakukan dengan sistem gadai tanah pertanian berdasarkan hukum adat yang dilakukan dengan memberikan jaminan pada pihak pemberi gada dan proses ini tidak sejalan dengan UU. Gadai tanah pertanian pada masyarakat Desa Ubung Kecamatan Jonggat Kabupaten Lombok Tengah tidak sejalan dengan gadai tanah pertanian yang diatur dalam Undang-Undang Nomor 56 Prp Tahun 1960. Faktor yang menghambat pelaksanaan gadai tanah pertanian di Desa Ubung Kecamatan Jonggat Kabupaten Lombok Tengah NTB berdasarkan pasal 7 ayat (1) dan ayat (2) UndangUndang Nomor 56 Prp Tahun 1960 tidak efektif adalah sebagai berikut: a. belum ada sosialisais Undang-Undang Nomor 56 prp Tahun 1960 yang mengatur mengenai masalah gadai tanah pertanian di Desa Ubung Kecamatan Jonggat Kabupaten Lombok Tengah NTB dari pihak berwenang, b. kultur masyarakat Desa Ubung Kecamatan Jonggat Kabupaten Lombok Tengah NTB yang menganggap ketentuan Undang-Undang Nomor 56 prp Tahun 1960 tidak sesuai dengan kebiasaan-kebiasaan yang terdapat dilingkungannya.
\end{abstract}

Kata kunci: Gadai Tanah; Hukum Adat; Undang-Undang; Pokok Agraria

\begin{abstract}
The issuance of Law Number 5 of 1960 concerning Basic Regulations on Agrarian Principles on September 24, 1960, then abolished the old agrarian law. The purpose of this study is to analyze the implementation of land pawns in the Ubung village, Jonggat sub-district and find out the inhibiting factors of the implementation of agricultural land pawns in Ubung Village, Jonggat District, Central Lombok Regency, West Nusa Tenggara based on Law No. 56 Prp of 1960. The method in this study is Empirical research methods and problem approaches using legal sociology. The results showed that the agricultural land pawn given by the pawnbroker and the pawn recipient was not in accordance with the law. Agricultural pawn in the community of Ubung Village, Jonggat Subdistrict, Central Lombok Regency is not in line with the agricultural land pawning regulated in Law Number 56 Prp of 1960. Factors that inhibit the implementation of agricultural pawn in Ubung Village, Jonggat Subdistrict, Central Lombok Regency NTB based on article 7 paragraph (1) and paragraph (2) of Law Number 56 Prp of 1960 ineffective are a) there has been no socialization of Law Number 56 prp of 1960 governing the problem of pawning agricultural land in Ubung Village, Jonggat District, Central Lombok Regency, NTB from the authorities. b) The culture of Ubung Village, Jonggat Subdistrict, Central Lombok Regency, NTB, which considers the provisions of Law Number 56 prp of 1960 to be incompatible with the customs contained in their environment.
\end{abstract}

Keywords: Land Pawn; Customary Law; Basic Agrarian Law 


\section{PENDAHULUAN}

Berdasarkan kehidupan masyarakat Indonesia secara khusus yang berada di suatu daerah yang tidak bisa terpisahkan oleh tradisi tradisional yang masih tetap dipertahankan dan dilestarikan sampai sekarang. Selain itu, hukum adat sebagai hukum asli masyarakat Indonesia yang menjadi pondasi hukum utama. Hukum agrarian adalah salah satu aspek hukum diberbagai bidang ilmu hukum yang tentunya tiap bidang memiliki hak-hak penguasaan berdasarkan atas bidang tanah atau sumber daya yang dapat dimiliki oleh siapapun dan hal tersebut termuat dalam pengertian dari agraria. Hukum agrarian merupakan sebuah hukum yang mengatur mengenai bidang tanah dan hanya terkait pada masalah pertanian, atau mengenai permukaan tanah dan kulit bumi saja. Hukum agrarian yang memiliki sumber pada hukum adat yang bersifat tidak tertulis, serta memiliki jiwa gotong - royong dapat memberi kejelasan pada hidup bermasyarakat (Thalib, 1985).

Masyarakat melakukan jual gadai sawah yang dimilikinya guna memenuhi kebutuhannya. Pegadaian secara populer dianggap memiliki suku bunga riba, tetapi biayanya seringkali rendah dibandingkan dengan yang terkait dengan alternatif seperti pinjaman gaji (Carter \& Skiba, 2013); (Kusairi, 2012); (Haryanto, 2010). Penggunaan pegadaian tersedia untuk siapa saja yang memiliki agunan (Carter, 2015); (Dalimunthe, 2018). Hal ini sesuai dengan hasil observasi yang menunjukkan bahwa ada beberapa orang masyarakat yang sedang menggarap sawah. Namun, ternyata sawah tersebut bukan hak miliknya melainkan hak pakai akibat dari melakukan jual beli gadai dengan pemilik sawah (Saptomo, 2010). Gadai sebagai salah satu kategori dari perjanjian utang-piutang, untuk suatu kepercayaan dari kreditur, maka debitur menggadaikan barangnya sebagai jaminan terhadap utangnya itu (Surahman \& Adam, 2018); Solusi atau tindakan yang harus dilakukan adalah sosialisasi masif kepada masyarakat dengan menggunakan strategi pemasaran yang efektif dan efisien (Edgina, Jazil, \& Nursyamsiah, 2016).

Mekanisme dalam tanah yang dijamin yakni tanah sawah atau tanah pertanian membuat masyarakat beralih pada perjanjian jual beli gadai yang ada di Desa Ubung masih menggunakan tradisi secara turun temurun. Gadai tanah kerap membuat penggadai mengalami kerugian bahkan tanah pertanian atau sawahnya tidak diperbolehkan digarap dan dilakukan aktivitas apapun lagi. Dengan adanya undangundang tersebut masih belum menjamin apa yang menjadi sumber permasalahan pada gadai tanah pertanian. Menurut (Miller, Hanke, \& Di, 2018) dalam penelitiannya mengatakan bahwa tidak ada bukti bahwa tingkat keterbacaan peraturan sesuai dengan jumlah pegadaian di negara bagian atau dengan langkah-langkah keramahan bisnis tingkat negara yang lebih luas. Sejalan dengan pendapat (Winarno, 2013) bahwa Undang-Undang Jaminan Fidusia berupaya memberikan suatu teknis perlindungan bagi kepentingan kreditur, sehingga memberikan posisi lemah bagi kreditur seperti tidak adanya ketegasan dalam eksekusi.

Terkait dengan isu penelitian ini, beberapa penelitian sebelumnya telah dilakukan, seperti (Hermawan, 2015) dalam penelitiannya mengenai tinjauan hukum islam terhadap penggunaan barang gadai di ikhsan rent krapyak kulon panggungharjo, sewon, bantul bagus menunjukkan bahwa ada pihak ketiga yang memberikan uang kepada pihak kedua untuk memanfaatkan barang jaminan (sepeda motor) milik pihak pertama. Kedua, (Abubakar, 2012) dalam penelitinanya mengatakan bahwa Praktik pergadaian, khususnya gadai emas syariah yang semula berfungsi sebagai alternatif pembiayaan yang cepat dan murah berbasis kekuatan sendiri bergeser menjadi saran investasi yang spekulatif. Selanjutnya, (Manahaar, 2019) dalam penelitianya mengenai implementasi gadai syariah (rahn) untuk menunjang perekonomian masyarakat di indonesia, menunjukkan bahwa praktik gadai syariah atau yang disebut rahn ini sangat menekankan tidak adanya pengenaan riba atau pungutan bunga atas pinjaman yang diberikan. Perjanjian gadai sebagai perjanjian tambahan keberadaannya ditujukan untuk mendukung perjanjian pokok, yakni perjanjian utang piutang, sehingga manakala pemberi gadai/debitor wanprestasi terhadap penerima gadai/kreditornya, maka berdasarkan parate executie yang dimiliki oleh penerima gadai, penerima gadai berhak melelang objek gadai (Adjie \& Saputro, 2015). Berdasarkan penjelasan di atas, maka tujuan penelitian ini yaitu menganalisis pelaksanaan gadai tanah di desa ubung kecamatan jonggat dan mengetahui faktor-faktor penghambat pelaksanaan gadai tanah pertanian di Desa Ubung Kecamatan Jonggat Kabupaten Lombok Tengah Nusa Tenggara Barat berdasarkan Undang-Undang Nomor 56 Prp Tahun 1960. 


\section{METODE PENELITIAN}

Pelitian ini menggunakan pendekatan normative yang menggunakan undang-undang sebagai data utama. Penelitian ini dilakukan di Desa Ubung kecamatan Jonggat kabupaten Lombok Tengah NTB. Dalam penelitian ini, sample yang digunakan adalah seluruh masyarakat desa Ubung yang dipilih secara acak. Oleh karena itu, sample yang dimaksud adalah pemegang gadai, pemberi gadai sebanyak, Kepala Desa Ubung sebagai informan. Teknik pengumpulan data dilakukan dengan menggunakan teknik wawancara dengan berpedoman pada daftar pertanyaan dalam bentuk kombinasi (tertutup dan terbuka). Kemudian, data yang diperoleh dianalisi secara kualitatif dengan menggunakan cara deskripsi melalui kata-kata.

\section{HASIL DAN PEMBAHASAN}

Pada pelaksanaannya gadai tanah yang terdapat pada penelitian ini masih menggunakan sistem gadai tanah pertanian berdasarkan hukum adat yang sudah turun - temurun. Gadai menurut pandangan masyarakat didaerah tersebut gadai tanah bisa dilakukan dengan memberikan jaminan pada pihak pemberi gadai.

Gadai tanah sawah ini telah berlangsung sejak lama. Namun, tidak diketahui tanggal pastinya sejak kapan, karena tidak tercatat (Sudiyat, 2007). Sebelum adanya transaksi gadai tanah sawah masyarakat desa Ubung mengambil tindakan untuk meminjam uang ke bank bahkan ke rentenir, karena prosesnya lama dan bunganya sangat besar membuat warga desa setempat kesulitan dalam mengurus persyaratan bahkan peminjaman uang di bank semakin memberatkan masyarakat karena besarnya bunga yang harus dibayar, maka untuk mempermudah masyarakat untuk mendapatkan dana demi mencukupi kebutuhannya, masyarakat banyak melakukan gadai tanah sawah, selain prosesnya cepat juga bisa mendapatkan uang tunai secara langsung dan tidak susah mengurus persyaratan yang harus dipenuhi seperti persyaratan di bank. Transaksi gadai tanah pertanian yang terjadi di Desa Ubung Kecamatan Jonggat Kabupaten Lombok Tengah NTB dalam pasal 7 ayat (1) dan ayat (2) UU No. 56 Prp tahun 1960 dengan ketidakefektifan yang menyebabkan terjadi secara sendiri tapi terdapat beberapa faktor yang mempengaruhi hal tersebut. Berdasarkan hal tersebut diatas maka adapun beberapa faktornya yakni:

1. Peraturan tersebut mengatur tentang gadai tanah persawahan di desa Ubung kecamatan Jonggat kabupaten Lombok Tengah NTB dari pihak berwenang belum melakukan penyuluhan atau sosialisasi kepada masyarakat. Pemberian sosialisasi berdasarkan pada undang-undang nomor 56 Prp tahun 1960 yang mengatur tentang permasalahan gadai tanah pertanian atau persawahan. Peraturan yang kurang jelas bahkan tidak memiliki efektifitas merupakan tugas dari berbagai pihak seperti dari pihak kepala desa, instansi pertanahan, pihak akademisi seperti dari perguruan tinggi, serta pejabat lain yang berwenang untuk mengkaji ulang mengenai apa yang menjadi permasalahan dimasyarakat serta memberikan sosialisasi secara berkala kepada masyarakat, dengan memberi sosialisasi masyarakat terhadap permasalahan yang dihadapi mereka secara khusus mengenai tanah, dan masyarakat terbantu untuk mendapatkan penjelasan atau informasi mengenai ketentuan gadai tanah.

Masyarakat desa Ubung Kecamatan Jonggat Kabupaten Lombok Tengah NTB pada umumnya tidak mengetahui ketentuan gadai tanah persawahan menurut Undang-undang nomor 56 Prp tahun 1960 yang berlaku, masyarakat hanya mengetahui ketentuan gadai tanah pertanian dalam kebiasaan-kebiasaan mereka lakukan berulang-ulang secara terus menerus hingga ditingkat turun temurun. Hal ini terlihat dalam hasil penelitian ini yang menunjukkan bahwasannya semua masyarakat pada penelitian ini baik pemberi gadai ataupun penerima gadai tanah pertanian tidak mengetahui sama sekali mengenai undang-undang yang mengatur mengenai masalah gadai tanah pertanian. Di desa Ubung kecamatan Jonggat kabupaten Lombok Tengah NTB sepanjang ketetapan undang- undang tersebut belum pernah ada sosialisasi yang terkait mengenai Undang-undang Nomor 56 Prp Tahun 1960 kepada masyarakat. Kepala desa Ubung kecamatan Jonggat kabupaten Lombok Tengah NTB menyebutkan bahwa tidak pernah ada sosialisasi kepada masyarakat desa Ubung kecamatan Jonggat kabupaten Lombok Tengah NTB terkait dengan ketentuan gadai tanah pertanian dari pihak manapun. Hal tersebut juga dibenarkan oleh seluruh subjek penelitian bahwa di desa Ubung kecamatan Jonggat kabupaten Lombok Tengah NTB memang belum pernah ada sosialisasi terkait aturan gadai tanah pertanian khususnya Undang-Undang Nomor 56 Prp Tahun 1960. Dari hasil penelitian menjelaskan bahwa selama ini di desa Ubung kecamatan Jonggat kabupaten Lombok Tengah NTB belum pernah diadakan sosialisasi mengenai Undang-Undang Nomor 56 Prp Tahun 
1960 baik itu dari pihak Kepala Desa atau dari instansi pemerintah yang berwenang. Tidak adanya sosialisasi mengenai ketentuan gadai tanah pertanian menjadikan masyarakat desa Ubung kecamatan Jonggat kabupaten Lombok Tengah NTB tidak mengetahui ketentuan gadai tanah pertanian berdasarkan Undang-Undang. Bahwa dengan dilakukannya penyuluhan dengan mengkaji pemahaman masyarakat akan terbantu untuk mengetahui ketentuan dari gadai tanah pertanian yang telah ditetapkan tersebut.

2. Budaya masyarakat Desa Ubung Kecamatan Jonggat Kabupaten Lombok Tengah NTB yang berpendapat bahwa ketetapan Undang - Undang Nomor 56 Prp Tahun 1960 tidak sesuai dengan kebiasaan - kebiasaan dalam lingkungannya. Dalam pelaksanaan gadai tanah pertanian masyarakat desa Ubung kecamatan Jonggat kabupaten Lombok Tengah NTB cenderung terpengaruh oleh ketentuan-ketentuan yang sudah menjadi kebiasaan dalam lingkungannya. Kebiasaan yang dimaksud oleh masyarakat Desa Ubung Kecamatan Jonggat Kabupaten Lombok Tengah NTB adalah perbuatan yang dilakukan secara berulang-ulang yang diikuti dan diterima oleh masyarakat secara terbuka bukan kebiasaan yang disertai dengan keyakinan akan kewajiban hukum dan adanya sanksi terhadap pelanggaran kewajiban hukum tersebut.

\section{KESIMPULAN DAN SARAN}

\section{Kesimpulan}

Pelaksanaan gadai tanah pertanian pada masyarakat desa Ubung kecamatan Jonggat kabupaten Lombok Tengah NTB, masih belum memiliki pengaruh atau tidak efektif bagi masyarakat, berdasarkan UndangUndang Nomor 56 Prp Tahun 1960. Karena masih memakai hukum adat atau kebiasaan, didalam transaksi gadai masih terdapat ketentuan tradisional atau kekeluargaan karena masih mempunyai sistem musyawarah terlebih dahulu dan pembayaran gadai tanah dapat dilakukan secara bertahap dan apabila terdapat masalah maish bisa diselesaikan secara adat dan secara kekeluargaan, khususnya di desa tersebut karena memiliki keeratan atara masyarakat. Ketentuan pasal pada undang-undang tersebut, secara yuridis formal telah membatalkan sistem gadai tanah pertanian yang telah berjalan di tengah- tengah masyarakat Desa Ubung Kecamatan Jonggat Kabupaten Lombok Tengah NTB masih memakai hukum adat. Transaksi gadai tanah pertanian yang dilakukan masyarakat Desa Ubung Kecamatan Jonggat Kabupaten Lombok Tengah NTB pada umumnya dilakukan kepada keluarga sendiri atau tetangga alasan masyarakat menggadaikan tanah pertaniannya kepada keluarga adalah karena dinilai memberikan kemudahan dan mendapatkan pinjaman uang untuk memenuhi kebutuhan yang mendesak.

Gadai tanah dapat dijaminkan oleh keluarga yang memiliki tanah persawahan atau pertanian yang digarap oleh keluarga dan adanya gadai sawah ini memberi manfaat tersendiri karena ada yang mendapatkan keuntungan karena mereka yang tidak memiliki modal dalam Bertani dengan menggadaikan maka mereka bisa termodali oleh adanya gadai sawah tersebut dan merekapun tetap bisa bertani atau berkebun. Keadaan mendesak dapat terjadi karena keadaan ekonomi maupun keadaan pasar yang tidak menentu karena faktor harga memiliki pengaruh terhadap petani dan hasil pertaniannya karena apabila harga pasar merosot rendah maka petani tidak mampu mencukupi keluarga bahkan memutar modalnya Kembali untuk melanjutkan pertaniannya. Pengaruh atau faktor gadai tanah pertanian menurut ketentuan pasal 7 ayat (1) dan ayat (2) Undang-Undang Nomor 56 Prp Tahun 1960 di Desa Ubung Kecamatan Jonggat Kabupaten Lombok Tengah NTB tidak efektif hal ini disebabkan oleh beberapa faktor penyebab sebagai berikut: Belum ada sosialisasi Undang-Undang Nomor 56 Prp Tahun 1960 yang mengatur mengenai masalah gadai tanah pertanian di Desa Ubung Kecamatan Jonggat Kabupaten Lombok Tengah NTB dari pihak berwenang. Budaya masyarakat Desa Ubung Kecamatan Jonggat Kabupaten Lombok Tengah NTB yang menganggap ketentuan Undang-Undang Nomor 56 Prp Tahun 1960 tidak sesuai dengan kebiasaan-kebiasaan yang terdapat dilingkungannya.

\section{Saran}

Pemerintah perlu mengadakan penyuluhan dengan melakukan sosialisasi dari pihak berwenang terkait hukum dibidang pertanahan secara khusus mengenai gadai tanah. Kurangnya perhatian pemerintah maupun pihak yang berwenang kepada masyarakat kecil menyebabkan masyarakat kerap mendapatkan 
berbagai kesulitan bahkan ketidak pahaman mengenai gadai tanah, dengan demikian perlu dilakukannya pengoptimalan sosialisasi mengenai peraturan-peraturan yang ada kepada masyarakat luas secara khusus masyarakat kecil yang berada jauh dari ibukota.

Masyarakat yang mengalami permasalahan gadai tanah pertanian diharapkan untuk mengulas atau memahami terlebih dahulu apa yang dimaksud dengan gadai tanah dan apabila melaksanakan gadai tanah pertanian sesuai dengan aturan yang telah dibuat oleh pihak yang berwenang yang mana aturan yang dibuat agar masyarakat dapat lebih mandiri mencari informasi mengenai apa yang menjadi masalah dan pengaturannya, karena apabila masyarakat tidak memiliki upaya mengetahui atau mengulas peraturan maka masyarakat tidak akan mudah mendapatkan penjelasan yang jelas mengenai gadai tanah pertanian. Apabila peraturan itu tidak diterapkan maka pihak-pihak yang terkait akan merasa dirugikan.

\section{DAFTAR PUSTAKA}

Abubakar, L. (2012). Pranata Gadai Sebagai Alternatif Pembiayaan Berbasis Kekuatan Sendiri (Gagasan Pembentukan UU Pergadaian). Mimbar Hukum, 24(1), 1-14. https://doi.org/10.22146/jmh.16146

Adjie, H., \& Saputro, E. H. (2015). Perlindungan Hukum Bagi Pemilik Objek Gadai Atas Pelelangan Objek Gadai. Hukum Bisnis, 1(1), 52-65. Retrieved from https://jurnal.narotama.ac.id/index.php/hukumbisnis/article/view/57\#: :text=Perlindungan hukum bagi pemilik objek gadai yang sesungguhnya atas pelelangan,digadaikan kepada pemilik yang sesungguhnya.

Carter, S. P. (2015). Payday Loan and Pawnshop Usage: The Impact of Allowing Payday Loan Rollovers. Journal of Consumer Affairs, 49(2), 436-456. https://doi.org/10.1111/joca.12072

Carter, S. P., \& Skiba, P. M. (2013). Pawnshops, Behavioral Economics, and Self-Regulation. Pawnshops and Behavioral Economics, 32, 193-220.

Dalimunthe, D. (2018). Objek Gadai Dalam Kitab Undang-Undang Hukum Perdata (BW): Dalimunthe, Dermina. Yurisprudentia; Jurnal Hukum Ekonomi, 4(1), 50-66. Retrieved from http://jurnal.iainpadangsidimpuan.ac.id/index.php/yurisprudentia/article/view/1497

Edgina, L., Jazil, T., \& Nursyamsiah, T. (2016). Strengthening the Role of Islamic Pawnshop in Islamic Financing for Micro Small and Medium Enterprises: ANP Approach. Tazkia Islamic Finance and Business Review, 10.1, 34-49. Retrieved from https://www.neliti.com/publications/271279/strengthening-the-role-of-islamic-pawnshop-in-islamicfinancing-for-msmes-anp-ap

Haryanto, B. S. (2010). Kedudukan Gadai Syariah (Rahn) Dalam Sistem Hukum Jaminan Indonesia. Jurnal Dinamika Hukum, 10(1), 22-27. https://doi.org/10.20884/1.jdh.2010.10.1.133

Hermawan, B. (2015). Tinjauan Hukum Islam terhadap Penggunaan Barang Gadai di Ikhsan Rent Krapyak Kulon Panggungharjo, Sewon, Bantul Bagus. Az Zarqa, 7(2), 181-200. Retrieved from http://ejournal.uin-suka.ac.id/syariah/azzarqa/article/view/1500

Kusairi, A. (2012). Konsep Gadai Dalam Hukum Islam. Al-Ihkam, 7(1), 116-141. Retrieved from http://ejournal.stainpamekasan.ac.id/index.php/alihkam/article/view/320

Manahaar, P. (2019). Implementasi Gadai Syariah (Rahn) Untuk Menunjang Perekonomian Masyarakat di Indonesia. Dialogia Iuridica: Jurnal Hukum Bisnis Dan Investasi, 10(2), 97-104. https://doi.org/10.28932/di.v10i2.1126

Miller, G., Hanke, S. A., \& Di, H. (2018). Pawnshops Regulatory Environment: A Readability Analysis. JABM (Journal of Accounting - Business \& Management), 1(25), 50-61. https://doi.org/10.31966/jabminternational.v1i25.329

Saptomo, A. (2010). Hukum dan Kearifan Lokal: Revitalisasi Hukum Adat Nusantara. Jakarta: Grasindo. Sudiyat, I. (2007). Asas-Asas Hukum adat: Bekal Pengantar. University of California: Liberty.

Surahman, M., \& Adam, P. (2018). Penarapan Prinsip Syariah Pada Akad Rahn Di Lembaga Pegadaian Syariah. Jurnal Law and Justice, 2(2), 135-146. https://doi.org/10.23917/laj.v2i2.3838

Thalib, S. (1985). Hubungan Tanah Adat dengan Hukum Agraria di Minangkabau. Jakarta: Bina Aksara. Winarno, J. (2013). Perlindungan Hukum Bagi Kreditur Pada Perjanjian Jaminan Fidusia: Winarno, 
Jurnal Preferensi Hukum

Vol. 1 No. 12020

Jatmiko. Jurnal Independent Fakultas Hukum, 1(1), 44-55. https://doi.org/10.30736/ji.v1i1.5 